\title{
The impact of workplace smoking bans: results from a national survey
}

Center for Economics Research, Research Triangle Institute, 3040 Cornwallis Rd, Research Triangle Park, North Carolina, USA

M C Farrelly

A E S Sfekas

Department of Economics, University of Maryland, Project HOPE and NBER W N Evans

Correspondence to: Dr M C Farrelly. email: mcf@rti.org.

Received 1 February 1999 Accepted 25 March 1999

\author{
Matthew C Farrelly, William N Evans, Andrew E S Sfekas
}

\begin{abstract}
Objective-To estimate the impact of workplace smoking restrictions on the prevalence and intensity of smoking among all indoor workers and various demographic and industry groups.

Design-Detailed cross sectional data on worker self reported characteristics, smoking histories, and workplace smoking policies were used in multivariate statistical models to examine whether workplace smoking policies reduce cigarette consumption. After analysing the distribution of policies, four main types of workplace programme were defined: (1) $100 \%$ smoke-free environments, (2) work area bans in which smoking is allowed in some common areas, (3) bans in some but not all work and common areas, and (4) minimal or no restrictions.
\end{abstract}

Setting-After environmental tobacco smoke was identified as a health hazard in the mid-1980s, workplace smoking restrictions became more prevalent. By 1993, nearly $82 \%$ of indoor workers faced some restriction on workplace smoking and $47 \%$ worked in $100 \%$ smoke-free environments.

Participants-The database included a nationally representative sample from the tobacco use supplements to the September 1992, January 1993, and May 1993 Current Population Surveys of 97882 indoor workers who were not self employed.

Main outcome measures-Prevalence of smoking and number of cigarettes smoked daily by smokers.

Results-Having a $100 \%$ smoke-free workplace reduced smoking prevalence by 6 percentage points and average daily consumption among smokers by $14 \%$ relative to workers subject to minimal or no restrictions. The impact of work area bans was lessened by allowing smoking in some common areas. Smoke-free policies reduced smoking for all demographic groups and in nearly all industries.

Conclusions-Requiring all workplaces to be smoke free would reduce smoking prevalence by $10 \%$. Workplace bans have their greatest impact on groups with the highest rates of smoking.

(Tobacco Control 1999;8:272-277)

Keywords: workplace; smoking ban; smoking restrictions

In 1986, both the Surgeon General and the National Academy of Science/National Re- search Council released reports identifying environmental tobacco smoke (ETS) as a cause of disease in non-smokers. Since that time, workplace smoking restrictions have proliferated. In $1985,38 \%$ of workers were employed by firms that had a policy to restrict smoking, and only $25 \%$ worked for firms that restricted smoking in immediate work areas (and allowed smoking in some common areas). ${ }^{1}$ By $1993,82 \%$ of workers were subject to some type of smoking restrictions: nearly $67 \%$ of workers were subject to immediate work area smoking restrictions, and $47 \%$ worked in a $100 \%$ smoke-free environment.

Although the primary objective of workplace smoking restrictions and bans may be to reduce ETS in the workplace, several studies have shown that these restrictions and bans also lead to a decrease in the prevalence of smoking and the number of cigarettes smoked daily among workers. ${ }^{1-9}$

In this paper we examine the impact of various workplace smoking policies using data from nationally representative surveys of roughly 100000 indoor workers. In general, our results indicate that more stringent workplace smoking policies will reduce smoking participation and smoking intensity. Our estimates suggest that compared with a workplace with only minimal or no restrictions, adopting a workplace $100 \%$ smoke-free policy leads to a 5.7 percentage point decline in the prevalence of smoking and a $14 \%$ decline in average cigarettes consumed daily among current smokers. Maintaining work area bans but allowing some smoking in common areas cuts these effects in half. Because previous studies have shown that workplace smoking bans are more prevalent in some types of industries and occupations and among particular demographic groups, ${ }^{10}$ we also examine the impact of these policies by race, age, sex, education, and industry of employment.

Smoke-free policies reduce smoking participation and intensity across all demographic groups in nearly all industries. We find that the greatest absolute reduction in smoking occurs for those groups or industries that have the highest prevalence of smoking and the highest daily consumption of cigarettes. In the final section of this paper, we simulate the effect on cigarette consumption of moving to a complete smoke-free workplace.

\section{Methods}

DATA

In our analyses we used data from tobacco use supplements to the September 1992, January 
Table 1 Descriptive statistics of selected variables, CPS 1992-1993

\begin{tabular}{lll}
\hline & $\begin{array}{l}\text { Indoor workers not self } \\
\text { employed }\end{array}$ & All workers \\
\hline Non-Hispanic white & $82.4 \%$ & $79.9 \%$ \\
Non-Hispanic African American & $8.2 \%$ & $9.5 \%$ \\
Hispanic & $5.4 \%$ & $7.5 \%$ \\
Other race/ethnicity & $3.9 \%$ & $3.2 \%$ \\
Female & $58.5 \%$ & $46.0 \%$ \\
Number in household & 2.97 & 3.10 \\
Age (years) & 38.7 & 39.0 \\
Hours worked/week & 36.7 & 37.2 \\
Real income (1997 dollars) & $\$ 30599$ & $\$ 30435$ \\
Income missing & $3.9 \%$ & $4.8 \%$ \\
Divorced & $11.5 \%$ & $10.1 \%$ \\
Widowed & $2.5 \%$ & $2.1 \%$ \\
Separated & $2.6 \%$ & $2.5 \%$ \\
Never married & $21.9 \%$ & $22.7 \%$ \\
High school dropout & $8.3 \%$ & $11.4 \%$ \\
High school graduate & $33.9 \%$ & $34.9 \%$ \\
Some college education & $28.9 \%$ & $28.0 \%$ \\
Graduated from college & $19.0 \%$ & $17.0 \%$ \\
Some graduate school education & $9.9 \%$ & $8.7 \%$ \\
Living in an MSA central city & $21.6 \%$ & $22.9 \%$ \\
Living in an MSA, not in a central city & $34.6 \%$ & $39.0 \%$ \\
Smokers & $25.0 \%$ & $25.1 \%$ \\
Cigarettes smoked daily by smokers & 19.2 & 20.2 \\
Number of observations & 97882 & 171680 \\
\hline
\end{tabular}

MSA $=$ Metropolitan Statistical Area.

Table 2 Distribution of work area and common area smoking bans *

\begin{tabular}{llll}
\hline & $\begin{array}{l}\text { Full common area } \\
\text { ban }\end{array}$ & $\begin{array}{l}\text { Partial common } \\
\text { area ban }\end{array}$ & $\begin{array}{l}\text { No common area } \\
\text { ban }\end{array}$ \\
\hline Full work area ban & $46.7 \%$ & $18.8 \%$ & $1.4 \%$ \\
Partial work area ban & $3.5 \%$ & $9.0 \%$ & $0.9 \%$ \\
No work area ban & $0.3 \%$ & $0.6 \%$ & $18.9 \%$ \\
\hline
\end{tabular}

«"Common areas" refers to public areas such as lobbies, rest rooms, etc at the workplace.

1993, and May 1993 Current Population Surveys (CPS). The CPS is a monthly national survey of approximately 57000 households conducted by the US Census Bureau for the Bureau of Labor Statistics. The CPS is the federal government's primary source of monthly labour market data such as unemployment rates. Households in the CPS are interviewed for the same four month period for two years. One quarter of the households leave the sample each month, either temporarily or permanently. The spacing of the tobacco use supplements generates three independent samples which are designed to be aggregated together.

The basic questions in the monthly CPS provide detailed information about individuals and their households. The tobacco use supplements contain questions about smoking histories as well as attitudes about smoking restrictions for all respondents age 15 years and older.† Questions concerning workplace smoking policies were only asked of workers who might be subject to such a policy (that is, indoor workers who were not self employed). These workers were asked whether their workplaces had a formal policy that restricted smoking; whether their firm allowed smoking in all, some, or no common areas (for example, lobbies, rest rooms); and whether the firm allowed smoking in all, some, or no work areas.

The three tobacco use supplements contain data on 275895 respondents age 18 years or older. For this study, we used data from only those individuals who (a) were aged 18 years or

tWe excluded 15 to 17 year old respondents because job turnover is high in this age group and the number of hours worked is relatively low- 15.6 hours a week. older, (b) were currently employed, (c) were not self employed, (d) worked indoors, (e) had a fixed work area, and (f) for whom we had complete smoking status and smoking policy data. $¥$ Workers were considered to be currently employed if they worked in the past week or would have worked if they had not been ill or on vacation. In table 1 , we report descriptive statistics using sampling weights for all workers aged 18 and older $(n=171680)$ as well as for our sample of indoor workers $(n=97882)$. Notice that the indoor sample was roughly the same age, was more educated, had a higher percentage of females, and had a lower fraction of minorities than the sample of all workers. In all, 24471 indoor workers $(25.0 \%)$ smoked at the time of the survey, and smokers reported smoking 19.2 cigarettes a day. These numbers are only slightly lower than the estimates for the full workforce.

To obtain information on workplace smoking policies, the survey first asked eligible respondents, "Does your place of work have an official policy that restricts smoking in any way?" Those who responded affirmatively were then asked, "Which of these best describes your place of work's smoking policy for indoor public or common areas, such as lobbies, rest rooms, and lunch rooms?" and "Which of these best describes your place of work's smoking policy for work areas?" The possible choices for respondents for both questions were, "Not allowed in any areas," "Allowed in some areas," or "Allowed in all areas."

In table 2, we summarise the prevalence of these policies for the indoor, non-selfemployed worker sample. We found that $46.7 \%$ of workers were subject to a $100 \%$ smoke-free policy, in which smoking is banned in both work and common areas. Nearly $67 \%$ were subject to smoking restrictions in their immediate work area but were allowed to smoke in some common areas. The percentage of indoor workers subject to no work area or common area restrictions was 18.9. Notice that those establishments with a common area ban were almost a complete subset of workers with work area bans-most firms ban common area smoking if they also ban work area smoking. In contrast, many workers cannot smoke in their work area but can smoke in some common areas. These results are nearly identical to those of Gerlach et $a l,{ }^{10}$ who reported the prevalence of workplace smoking policies for a similar sample of workers with the exception that they also included workers aged 15 to 17 from the CPS 1992-1993 tobacco use supplements.

ANALYSIS

Given the distribution of workplace smoking restrictions described in table 2 , we used four groups to describe workplace policies: (1) smoke-free workplaces (smoking was banned in work and common areas); (2) work area ban

¥This final restriction eliminated proxy responses from our analysis. The CPS often relies heavily on proxy responses; however, for the tobacco use supplements an effort was made to reduce proxy responses. In the overall sample, before imposing the restrictions (a)-(f), roughly $18 \%$ of responses were by proxy. 
Table 3 Normalised probit and ordinary least squares estimates, full model*

\begin{tabular}{lll}
\hline & Smoking participation $(n=97$ 882) & Cigarettes/day† ( $n=19$ 956) \\
\cline { 2 - 3 } & Coefficient (95\% confidence interval) & \\
\hline Smoke-free workplace & $-0.057(-0.065$ to -0.049$)$ & $-2.67(-3.05$ to -2.28$)$ \\
Work area ban and any common area restrictions & $-0.026(-0.035$ to -0.017$)$ & $-1.48(-1.89$ to -1.08$)$ \\
Partial work area and partial common area restrictions & $0.005(-0.007$ to 0.016$)$ & $-0.57(-1.08$ to -0.05$)$ \\
Dependent variable mean & 0.250 & 19.3 \\
\hline
\end{tabular}

*Also included but not shown were controls for household size; log of real income; an indicator for income missing; marital status; length of work week; education; race; month of survey; and state, industry, and occupation indicators.

†Cigarettes/day models include only smokers in the sample.

(smoking was allowed in some common areas); (3) partial work and common area restrictions; and (4) minimal or no restrictions. The final category was our reference category for multivariate analyses. To quantify the impact of these restrictions on the prevalence of smoking, we estimated probit models in which the dependent variable is an indicator that equals 1 if the respondent is currently a smoker and 0 otherwise. We also used ordinary least squares models to estimate the impact of smoking restrictions on daily cigarette consumption.

The covariates of interest in both the probit and linear models are indicator variables characterising the first three policies listed above. To control for the fact that certain types of workers may be more or less likely to work in establishments with smoking restrictions, we exploited the rich demographic data in the CPS and added an extensive list of other cofactors, including age; age squared; inflation adjusted family income and an indicator for income not reported; household size; sex; four indicators for education (high school dropout, some college, college graduate, some postgraduate work); three indicators for race (non-Hispanic whites, non-Hispanic African Americans, and Hispanics); indicators for living in urban and central urban areas; four indicators for marital status (divorced, widowed, separated, never married); an indicator for the year of survey; five indicators for number of hours worked per week (0-19, $20-29,30-39,40-49, \geqslant 50)$; and indicators for state of residence, occupation, and industry groups. There were 13 occupation and 22 industry group indicator variables to control for industry and occupation specific characteristics that are not captured by the other covariates.

Following the work of Gerlach et $a l,{ }^{10}$ who report that the prevalence of workplace smoking policies varies by observed characteristics, we estimated separate models of the impact of smoking policies on smoking behaviour for sex, race, age, education, and industry groups. We separated the sample into (1) three age groups-young adults aged 18 to 24 , adults aged 25 to 39 , and adults aged 40 to 65 ; (2) four education groups-high school dropouts, high school graduates, those with some college experience, and college graduates; and (3) six industry groups, using standard industrial classification (SIC) codes-wholesale and retail trade; manufacturing; transportation, common utilities, and communication; medical services; finance, insurance, and real estate; and other professions (for example, law, education, architecture).

For each of the multivariate probit models, we estimated the marginal effects for each of the workplace smoking policies. The marginal effects yield the percentage point change in the prevalence of smoking generated by moving from no or minimal restrictions to a $100 \%$ smoke-free workplace. To determine the impact of the workplace policies on the number of cigarettes smoked daily by smokers, we estimated ordinary least squares models. The results of these models yield the change in the average number of cigarettes as a result of implementing any of the three more restrictive smoking policies relative to having no or minimal smoking restrictions. Although we estimated several models for demographic subpopulations, each model includes the extensive list of covariates listed above, with the exception of the stratifying variable (for example, race, sex).

\section{Results}

The results for the full sample of indoor workers are reported in table 3 . In column 1 , we report the marginal effects of the workplace policy indicators from the smoking participation probit models. Next to each parameter estimate, we present the $95 \%$ confidence interval (CI). In column 2, we report the coefficient on the policy dummy variable from the ordinary least squares model, where the dependent variable is cigarettes per day for the sample of smokers.

These results show that moving from no smoking restrictions to a smoke-free workplace decreased the prevalence of smoking by 5.7 percentage points ( $95 \% \mathrm{CI}=4.9$ to 6.5$)$ and reduced daily consumption among the remaining smokers by 2.67 cigarettes $(95 \% \mathrm{CI}=2.28$ to 3.05$)$. The former result is a $22.8 \%$ reduction in smoking prevalence compared to the sample mean, while the latter represents a nearly $14 \%$ decrease in average daily cigarette consumption. Maintaining work area bans but allowing smoking in common areas reduced the impact of work area bans by half. For these workplaces, we observed a 2.6 percentage point decrease in the prevalence of smoking and a decline of 1.48 cigarettes in the average daily consumption ( $95 \% \mathrm{CI}=1.08$ to 1.89 ). Partial workplace and common area bans had no statistically significant effects on the prevalence of smoking. However, these restrictions decreased daily consumption among remaining smokers (those who do not quit smoking) by a modest 0.57 cigarettes $(95 \% \mathrm{CI}=0.05$ to 
Table 4 Normalised probit and ordinary least squares estimates for smoke-free workplace policies: selected demographic groups

\begin{tabular}{|c|c|c|c|c|c|c|}
\hline \multirow[b]{2}{*}{ Sample } & \multicolumn{4}{|c|}{ Sample mean } & \multicolumn{2}{|l|}{ Smoke-free workplace } \\
\hline & Sample size & $\begin{array}{l}\text { Smoke-free } \\
\text { policy }\end{array}$ & $\begin{array}{l}\text { Current } \\
\text { smoker }\end{array}$ & $\begin{array}{l}\text { Cigarettes/ } \\
\text { day }{ }^{\star}\end{array}$ & Current smoker probit $(95 \%$ CI) & $\begin{array}{l}\text { Cigarettes/day* } \\
(95 \% \mathrm{CI})\end{array}$ \\
\hline \multicolumn{7}{|l|}{ By race } \\
\hline Non-Hispanic white & 80679 & $47.00 \%$ & $25.55 \%$ & 20.2 & $-0.062(-0.071$ to -0.053$)$ & $-2.78(-3.21$ to -2.36$)$ \\
\hline Non-Hispanic African American & 7996 & $43.73 \%$ & $24.37 \%$ & 13.7 & $-0.035(-0.064$ to -0.006$)$ & $-1.50(-2.74$ to -0.26$)$ \\
\hline Hispanic & 5231 & $45.28 \%$ & $20.23 \%$ & 12.7 & $-0.015(-0.045$ to 0.014$)$ & $-2.91(-4.70$ to -1.13$)$ \\
\hline Other race/ethnicity & 3850 & $48.57 \%$ & $21.24 \%$ & 16.0 & $-0.057(-0.092$ to -0.022$)$ & $-1.37(-3.35$ to 0.62$)$ \\
\hline \multicolumn{7}{|l|}{ By age (years) } \\
\hline $18-24$ & 11696 & $39.33 \%$ & $24.90 \%$ & 16.5 & $-0.078(-0.100$ to -0.056$)$ & $-1.72(-2.64$ to -0.80$)$ \\
\hline $25-39$ & 43049 & $46.50 \%$ & $26.53 \%$ & 18.7 & $-0.045(-0.057$ to -0.032$)$ & $-2.32(-2.84$ to -1.80$)$ \\
\hline $40-65$ & 40842 & $48.91 \%$ & $24.01 \%$ & 20.8 & $-0.062(-0.074$ to -0.049$)$ & $-3.43(-4.11$ to -2.75$)$ \\
\hline \multicolumn{7}{|l|}{ By sex } \\
\hline Male & 40599 & $39.90 \%$ & $26.11 \%$ & 21.2 & $-0.059(-0.065$ to -0.043$)$ & $-2.94(-3.56$ to -2.32$)$ \\
\hline Female & 57283 & $51.52 \%$ & $24.21 \%$ & 17.9 & $-0.054(-0.065$ to -0.043$)$ & $-2.38(-2.86$ to -1.90$)$ \\
\hline \multicolumn{7}{|l|}{ By education (for age $\geqslant 25$ years) } \\
\hline$<$ High school & 6751 & $29.70 \%$ & $40.79 \%$ & 20.1 & $-0.056(-0.093$ to -0.020$)$ & $-3.90(-5.19$ to -2.61$)$ \\
\hline High school graduate & 29070 & $39.17 \%$ & $32.22 \%$ & 19.7 & $-0.061(-0.077$ to -0.044$)$ & $-2.86(-3.45$ to -2.27$)$ \\
\hline Some college & 23504 & $49.48 \%$ & $25.92 \%$ & 18.9 & $-0.061(-0.078$ to -0.044$)$ & $-2.44(-3.27$ to -1.61$)$ \\
\hline College graduate & 17193 & $57.78 \%$ & $14.10 \%$ & 18.2 & $-0.040(-0.056$ to -0.024$)$ & $-1.69(-3.04$ to -0.35$)$ \\
\hline \multicolumn{7}{|l|}{ By industry } \\
\hline Wholesale and retail trade & 19756 & $30.35 \%$ & $30.48 \%$ & 19.4 & $-0.079(-0.097$ to -0.061$)$ & $-2.64(-3.40$ to -1.90$)$ \\
\hline Manufacturing & 19426 & $32.82 \%$ & $29.80 \%$ & 20.7 & $-0.058(-0.078$ to -0.039$)$ & $-2.82(-3.59$ to -2.05$)$ \\
\hline $\begin{array}{l}\text { Transportation, common utilities, } \\
\text { communication }\end{array}$ & 5337 & $46.77 \%$ & $25.41 \%$ & 20.1 & $-0.058(-0.094$ to -0.022$)$ & $-2.80(-4.64$ to -0.95$)$ \\
\hline Medical services & 11480 & $73.28 \%$ & $22.80 \%$ & 17.4 & $-0.010(-0.041$ to 0.022$)$ & $-1.46(-2.97$ to 0.05$)$ \\
\hline Finance, insurance, real estate & 7479 & $54.49 \%$ & $20.99 \%$ & 17.6 & $-0.052(-0.080$ to -0.025$)$ & $-3.87(-5.23$ to -2.50$)$ \\
\hline Other professionals & 18218 & $65.04 \%$ & $14.40 \%$ & 17.5 & $-0.035(-0.051$ to -0.019$)$ & $-3.02(-4.31$ to -1.74$)$ \\
\hline
\end{tabular}

${ }^{\star}$ Cigarettes/day models include smokers only in the sample.

$\mathrm{CI}$, confidence interval.

1.08). These results show a consistent pattern: the more restrictive the workplace policy, the greater the decline in smoking.

We examined whether the impact of $100 \%$ smoke-free policies varied by the type of worker and their industry by estimating the models from table 3 for several subpopulations. These results are reported in table 4. We first examined differences by racial/ethnic background. We estimated models for four groups: non-Hispanic whites ( $\mathrm{n}=80679$ ), non-Hispanic African Americans ( $\mathrm{n}=7996)$, Hispanics $(n=5231)$, and those of other race/ ethnicity ( $\mathrm{n}=3850)$. A $100 \%$ smoke-free policy decreased the prevalence of smoking (average daily consumption) for non-Hispanic whites by 6.2 percentage points (2.78 cigarettes), for non-Hispanic African Americans by 3.5 percentage points (1.50 cigarettes), for Hispanics by 1.5 percentage points (2.9 cigarettes), and those of other races/ethnicities by 5.7 percentage points ( 1.37 cigarettes). All these effects were statistically significant except for the impact of bans on smoking prevalence in the Hispanic population.

The effect of a workplace smoking ban also varied across age groups. For all groups, the impact of the ban on smoking prevalence and intensity was large and statistically significant. Young adults aged 18 to 24 , who have the lowest average daily consumption, experienced the smallest decline in daily consumption (1.72 cigarettes), while relatively older workersthose aged 40 to 65, who have the highest average daily consumption-experienced the largest decline in daily consumption (3.43 cigarettes). The effects for workers aged 25 to 39 fell in between the other two age groups. This pattern holds even when the declines are expressed as a fraction of current average daily consumption. The percentage declines from the lowest to highest age groups were $10.4 \%$, $12.4 \%$, and $16.5 \%$, respectively. These results stand in contrast to what economists have found for the effect of increasing cigarette excise taxes, where the largest declines are among young people and the smallest declines among those 40 and over. ${ }^{11} 12$

The impact of the ban on prevalence was not as systematic across age groups-the prevalence of smoking decreased by 7.8 percentage points for young adults, 4.5 percentage points for workers age 25 to 39, and 6.2 percentage points among workers age 40 to 65. Table 4 also shows only slightly larger effects of a complete smoking ban for men relative to women for both the prevalence of smoking and daily smoking.

Our results show dramatic differences in the prevalence of smoking by educational attainment: those with postgraduate education had both a lower prevalence of smoking and a lower daily consumption. Because many young adults are still in formal education, we limited the sample of workers to those aged 25 and older, when many have completed their education. Although the percentage point declines in the prevalence of smoking in response to a smoke-free environment were fairly uniform across educational groups, as a percentage of current rate of smoking, the largest effects (percentage decline) were for workers with a college degree $(28.4 \%$ decline $)$ and the least for high school dropouts (13.7\% decline). However, the opposite is true for the effects of the smoking ban on average daily consumption - those with less than a high school degree had the largest decline both in absolute terms (3.90 cigarettes) and as a percentage of average daily consumption $(19.4 \%)$. Those with a college degree decreased daily consumption by an average of 1.69 cigarettes, a $9.3 \%$ decline.

Finally, we examined the effects of smoking bans on selected industry groups. Once again, the workplace smoking ban had its greatest 
impact on the group (wholesale and retail trade) with the highest prevalence of smoking $(30.5 \%)$. The impact of a complete smoking ban on the prevalence of smoking was 7.9 percentage points, or a $25.9 \%$ decline. The group with the smallest decline in both absolute $(-1.0$ percentage point) and relative terms ( $4.4 \%$ drop) was the medical services industry. This result may reflect the fact that hospitals and others in the medical industry banned workplace smoking before the 1992/1993 CPS surveys, so we would not expect to see a large impact of workplace smoking policy changes. However, this group did not have the lowest prevalence of smoking of all the industry groups. The group "other professionals" had the lowest prevalence of smoking and responded to the smoking ban with a 3.5 percentage point (or $24.3 \%$ ) decline in the prevalence of smoking.

The industry group with the largest absolute drop in average daily consumption was the finance, insurance, and real estate industry group, with an average drop of 3.87 cigarettes a day (relative drop 22.0\%). This group is followed by "other professionals," with a drop of 3.02 cigarettes a day. The group with the smallest drop in absolute (1.46 cigarettes per day) and relative $(8.4 \%)$ terms was the medical services industry group.

The small impact in the medical field has some important implications for previous work in this field. Many of the studies that have examined the impact of policies in individual company settings have used data from hospitals. ${ }^{9}$ The results from table 4 suggest that these studies may not be particularly informative about other industries.

\section{Discussion}

Using a national representative sample of roughly 100000 indoor workers, we found that smoke-free workplace policies reduce the prevalence and intensity of smoking. Furthermore, we found these policies to be an effective tool for reducing smoking among the young and old, men and women, whites and ethnic/racial minorities, and more and less educated people, as well as across various industries.

As with most studies that use cross sectional data, it is difficult to assess whether there is a causal relation between workplace smoking bans and smoking. Some have expressed concern that analyses such as the one presented here may be subject to selection bias. ${ }^{810}$ The bias may take several forms: smokers are attracted to firms with lax smoking restrictions; firms with low rates of smoking are more likely to adopt workplace smoking restrictions; and firms that adopt workplace smoking restrictions may place a greater emphasis on the health and safety of their employees, so policies that restrict or ban smoking may simply reflect other programmes adopted by the firms. If firms with a workplace smoking ban also offer exercise programmes, on site exercise facilities, and smoking cessation programmes, smoking may be lower because of these other programmes, not because of the smoking ban.

Recent work by Evans et al addressed this issue in detail. ${ }^{1}$ Using data from national surveys (CPS and national health interview surveys), the authors used instrumental variable techniques to address the sources of potential bias and found that the single equation results were not subject to bias. They also produced results that are consistent with a causal relation by demonstrating that the impact of smoking bans increased monotonically for workers with longer work weeks. In other words, the longer their work week and the longer they were subject to restrictive smoking policies, the less likely they were to smoke.

In addition, in this paper we find other results that are consistent with a causal relation. First, tobacco use declines as the stringency of workplace policy increases. Adopting a $100 \%$ smoke-free policy leads to declines in smoking that are twice as great as banning smoking in all work areas but allowing smoking in some common areas. Second, we would expect the impacts of complete bans to be greatest for subgroups with the highest daily consumption, which is exactly what we found. Pooling the results across all of the various models in table 4 and estimating the correlation coefficient between the prevalence of smoking and the percentage point decline in smoking as a result of a smoking ban yield a coefficient of $0.45(p \leqslant 0.05)$. Estimating the correlation between average daily consumption and the absolute decline in daily consumption in response to a ban is $0.72(\mathrm{p} \leqslant 0.005)$. $\neq$ Although Gerlach et al found that workplace smoking restrictions appear systematically in the population, ${ }^{10}$ controlling for the detailed list of covariates in our models, including industry and occupation controls, still indicates a substantial impact of workplace smoking restrictions. Finally, many studies make use of longitudinal data and other methods to demonstrate a causal relation between workplace smoking bans and decreased smoking. ${ }^{1279}$ The advantage of using a large nationally representative survey is that the large sample sizes allow us to explore the differential effects that workplace smoking polices have on demographic subgroups of interest.

Although a large fraction of workers are employed in smoke-free workplaces, significant reductions in smoking can be achieved by the remaining establishments adopting smoke-free policies. Using the results presented in table 3, we simulated the effect of applying workplace smoking bans to workplaces that do not yet have complete bans. The predicted overall drop in the prevalence of smoking is 2.6 percentage points, or a $10 \%$ drop from the current level of smoking. The predicted decrease

¥If we express the declines in smoking in relative terms, we find similar results for average daily consumption. The correlation coefficient between the relative decline in daily consumption and average daily consumption is $0.56(p \leqslant 0.01)$. When we express declines in prevalence in response to smoking bans, the correlation between the decline in smoking and current prevalence is no longer statistically significant $(p \leqslant 0.37)$. 
in daily consumption is around $7 \%$ overall. This proposal has an effect roughly equivalent to the recently considered $\$ 1.10$ per pack increase in the price of cigarettes. Assuming an overall price elasticity of -0.40 , a tax increase of this magnitude would raise the price of cigarettes by roughly $50 \%$ and decrease daily cigarette consumption by $10 \%$ and the prevalence of smoking by $10 \% .{ }^{11}{ }^{13}$ Although price increases have the additional benefit of reducing smoking among non-workers, workplace smoking bans have other considerable benefits such as reduced exposure to ETS.

This work was supported by grants from the Robert Wood Johnson Foundation and the National Cancer Institute. We would like to thank Dr. Paul Royce for helpful suggestions.

1 Evans WC, Farrelly MC, Montgomery E. Do workplace smoking bans reduce smoking? Am Econ Rev (in press).

2 Stillman FA, Becker DM, Swank RT, et al. Ending smoking at the Johns Hopkins Medical Institutions. IAMA at the Johns Hor

3 Baile WF, Gibertini M, Ulschak F, et al. Impact of a hospital smoking ban: changes in tobacco use and employee attitudes. Addict Behav 1991;16:419-26.
4 Kinne S, Kristal AR, White E, et al. Work-site smoking policies: their population impact in Washington state. Am $\mathcal{F}$ cies: their population impact

5 Petersen D, Massengill D. Smoking regulations in the workplace: an update. Personnel: May 1996.

6 Sorensen R, Rigotti N, Rosen A, et al. Effects of a worksite nonsmoking policy: evidence for increased cessation. Am 7 Public Health 1991;81:202-4.

7 Stave GM, Jackson GW. Effect of a total work-site smoking ban on employee smoking and attitudes. F Occup Med 1991;33:884-90.

8 Woodruff TJ, Rosbrook B, Pierce J, et al. Lower levels of cigarette consumption found in smoke-free workplaces in California. Arch Intern Med 1993;153:1485-93.

9 Longo DL, Brownson RC, Johnson JC, et al. Hospital smoking bans and employee smoking behavior. FAMA 1996;275:1252-7.

10 Gerlach KK, Shopland DR, Hartman AM, et al. Workplace smoking policies in the United States: results from a national survey of more than 100000 workers. Tobacco Control 1997;6:199-206.

11 Centers for Disease Control. Response to increases in cigarette prices by race/ethnicity, income, and age groups United States, 1976-1993. MMWR 1998;47:605-9.

12 Evans WC, Farrelly MC. The compensating behavior of smokers: taxes, tar and nicotine. RAND f Econ 1998; 29:578-95.

13 Evans WN, Ringel JS, Stech D. Tobacco taxes and public policy to discourage smoking. In: Poerba J, ed. Tax policy and the economy, vol 13. Cambridge, Massachusetts: National Bureau of Economic Research, 1999. 